\section{Tropical Journal of Ophthalmology and Otolaryngology}

2020 Volume 5 Number 7 September-October

\title{
Hyperthyroidism associated with intraocular pressure and dry eye
}

\author{
Patil M. ${ }^{1}$, Gitanjali M. ${ }^{2 *}$ \\ DOI: https://doi.org/10.17511/jooo.2020.i07.03 \\ 1 Madhuri Patil, Assistant Professor, Department of Ophthalmology, Kamineni Academy of Medical Sciences and Research Centre, LB Nagar, \\ Hyderabad, India. \\ 2* Gitanjali M, Assistant Professor, Osmania Medical College/ Sarojini Devi Eye Hospital, Hyderabad, Telangana, India.
}

Graves' orbitopathy/ophthalmopathy (GO) also known as thyroid eye disease (TED), dysthyroid/thyroid-associated ophthalmopathy (TAO), is an autoimmune disorder representing the commonest and most important extrathyroidal manifestation of Graves' disease. Materials and Methods: This is a prospective study conducted for 2 years. A total of 60 established cases of Hyperthyroidism of all Age groups with either gender subjects who were diagnosed with Thyroid orbitopathy at hospitals were included in this study. History of ocular surgery or medications, those demonstrating the recent use of contact lenses, pregnant or lactating women. All the cases with similar presentation not proved to be Thyroid Orbitopathy and patients who did not report for the follow-up were excluded from the study. Result: A total of 60 patients were examined. Of the 60 cases analyzed, female preponderance was noted and 41-60 years age group had the highest incidence of thyroid orbitopathy. The most common presentation was found to be unilateral. Inferior rectus muscle was the commonest muscle involved with $48.3 \%$ followed by Medial rectus muscle $38.3 \%$, Superior rectus muscle $23.3 \%$, and Lateral rectus muscle involved least with $11.6 \%$ in descending order. None of the patients reported a loss of vision. Conclusions: Dry eye and increased IOP have commonly seen outcomes that should be managed diligently. This potential sight-threatening condition is seen worldwide and has many functional and cosmetic consequences that need to be recognized. Hyperthyroidism was significantly associated with the severity.

Keywords: Hyperthyroidism, Intraocular pressure, Thyroid eye disease

\section{Corresponding Author}

Gitanjali M, Assistant Professor, Osmania Medical College/ Sarojini Devi Eye Hospital, Hyderabad, Telangana, India.

Email: drgitanjali.m@gmail.com
How to Cite this Article

Patil M, Gitanjali M. Hyperthyroidism associated with intraocular pressure and dry eye. Trop J Ophthalmol Otolaryngol. 2020;5(7):183-189.

Available From

https://opthalmology.medresearch.in/index.php/jooo /article/view/167
To Browse

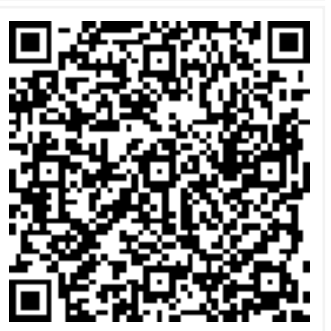

Manuscript Received 2020-10-09

Conflict of Interest No
Review Round 1 2020-10-14

Funding
Review Round 2 2020-10-16

Ethical Approval Yes
Review Round 3

Plagiarism X-checker $9 \%$
Accepted 2020-10-19

Note

(c) 2020 by Madhuri Patil, Gitanjali M and Published by Siddharth Health Research and Social Welfare Society. This is an Open Access article licensed under a Creative Commons Attribution 4.0 International License https://creativecommons.org/licenses/by/4.0/ unported [CC BY 4.0]. 


\section{Introduction}

Graves' orbitopathy/ophthalmopathy (GO) also known as thyroid eye disease (TED), dysthyroid/ thyroid-associated ophthalmopathy (TAO), is an autoimmune disorder representing the commonest and most important extrathyroidal manifestation of Graves' disease, but it may occur in patients without current or prior hyperthyroidism (euthyroid or ophthalmic Graves' disease) or in patients who are hypothyroid due to chronic autoimmune (Hashimoto's) thyroiditis [1].

Clinical symptoms and signs are usually mild, consisting of ocular irritation with redness and tearing, stare due to lid retraction and exophthalmos, and periorbital swelling [2]. Approximately $28 \%$ of $\mathrm{GO}$ cases are severe, with restricted motility leading to diplopia, exposure keratopathy, and optic neuropathy [3]. Patients with severe GO may have lower rates of remission of their thyroid disease compared to mild GO patients [4].

Graves' disease is a common disorder with an annual incidence in women of one per 1,000 population. In addition to hyperthyroidism, clinical involvement of the eyes develops in $25 \%$ to $50 \%$ of individuals with Graves' disease [5]. The annual incidence of Graves's ophthalmopathy in women is approximately 16 in 100,000 and men 3 in 100,000. There appears to be a female preponderance in which women are affected 2.5-6 times more frequently than men; however, severe cases occur more often in men than in women [6].

Also, most patients are aged 30-50 years, with severe cases appearing to be more frequent in those older than 50 years. It is the most common cause of bilateral exophthalmos, accounting for $85 \%$ of cases [7]. GO also presents as unilateral exophthalmos, accounting for $15-28 \%$ of cases [8]. Although many patients are thought to have unilateral disease based on clinical findings, radiographic evidence of bilateral disease is present in a majority [8]. Cigarette smoking has been considered the strongest risk factor for developing GO [9].

The underlying pathophysiology is thought to be an antibody-mediated reaction against the TSH receptor with orbital fibroblast modulation of T- cell lymphocytes. The T-cell lymphocytes are believed to react against thyroid follicular cells with shared antigenic epitopes in the retrobulbar space [10].
The lymphocytic infiltration leads to the activation of cytokine networks and inflammation and interstitial edema of the extraocular muscles [11]. Excess secretion of glycosaminoglycans by orbital fibroblasts seems to be an important contributor. The result is the expansion of the volume of extraocular muscles, retrobulbar fat, and connective tissue. Similar changes affect the eyelids and anterior periorbital tissues [12].

Risk factors of progressive and severe thyroidassociated orbitopathy:

01 . Age greater than 50 years a

02. Rapid onset of symptoms under 3 months

03. Cigarette smoking

04. Diabetes

05. Severe or uncontrolled hyperthyroidism

06. Presence of pretibial myxedema

07. High cholesterol levels (hyperlipidemia)

08. Peripheral vascular disease

\section{Aims and Objectives}

01. To study the different types of ocular manifestation of thyroid disease

2. To assess the risk factors associated with TED

\section{Materials and Methods}

This is a prospective study conducted over 2 years (September 2018 - August 2020).

Inclusion criteria: All the Age groups with either gender subjects who were diagnosed with Thyroid orbitopathy at hospitals were included in this study.

Exclusion criteria: History of ocular surgery or medications, those demonstrating the recent use of contact lenses, pregnant or lactating women. All the cases with similar presentation not proved to be Thyroid Orbitopathy and patients who did not report for the follow-up were excluded from the study.

A total of 60 established cases of Hyperthyroidism were the sample size. Sociodemographic features, clinical history, ocular symptoms, and associated systemic diseases, duration of thyroid disease, and treatment history were taken. The diagnosis of Hyperthyroidism was based on clinical and laboratory findings of diffuse enlargement of the thyroid gland, raised free thyroxin or triiodothyronine levels, and suppressed thyroidstimulating hormone levels. 
A comprehensive ophthalmic examination was performed in a standardized way for all patients. Best-corrected visual acuity was documented by the Snellen chart. Intraocular pressure (IOP) was measured by Goldmann applanation tonometry in the primary position. Eyelid, conjunctiva, and ocular motility were assessed. Tear status was evaluated with the Schirmer test and tear break-up time. considered Schirmer $<10 \mathrm{~mm}$ and tear break-up time $<10$ seconds as tear dysfunction. The degree of proptosis was measured by the Hertel ophthalmometer. Proptosis was defined as the measurement of protrusion of the globe $>20 \mathrm{~mm}$ from the lateral orbital rim in either eye or any discrepancy in the degree of protrusion of the 2 eyes by $>2 \mathrm{~mm}$. The fundus examination was done for the evaluation of the disc and retina.

Apart from the routine hematological examinations, the patient was subjected to serological investigations which include the Thyroid profile was also done. Once the case was confirmed to be of thyroid orbitopathy, depending on the stage of clinical presentation, the patients were reassured and observed. All patients were referred to an endocrinologist for management of thyroid dysfunction and then they were followed for 6 months. The first follow-up was in the 1 st week and then at 1st, 3rd, and 6th months.

Statistical analysis: The recorded observations were analyzed using SPSS Version 20. Categorical variables were expressed as counts and percentages. The Chi-square test for independent proportions or Fisher's exact test was used. $\mathrm{P}<0.05$ is considered statistically significant

\section{Result}

A total of 60 patients were examined. Of the 60 cases analyzed, female preponderance was noted as shown in Table 1.

Table-1: Sex distribution of patients.

\begin{tabular}{|l|l|l|}
\hline \multicolumn{1}{|c|}{ Sex } & \multicolumn{1}{c|}{ No. of patients } & \multicolumn{1}{c|}{ Percentage } \\
\hline Male & 21 & 35 \\
\hline Female & 39 & 65 \\
\hline Total & 60 & 100 \\
\hline
\end{tabular}

Table-2: Age distribution of patients.

\begin{tabular}{|l|l|l|}
\hline \multicolumn{1}{|c|}{ Age group } & \multicolumn{1}{c|}{ No. of patients } & \multicolumn{1}{c|}{ Percentage } \\
\hline$<20$ & 3 & 5 \\
\hline $21-40$ & 21 & 35 \\
\hline $41-60$ & 27 & 45 \\
\hline$>61$ & 7 & 11.6 \\
\hline
\end{tabular}

According to Table 2, 41-60 years age group had the highest incidence of thyroid orbitopathy, the patients were arbitrarily divided into four groups, and at least one less than 20 years of age group.

Table-3: Demographic details and clinical characteristics of study participants $(\mathrm{N}=60)$.

\begin{tabular}{|l|l|l|l|}
\hline & $\begin{array}{c}\text { Age (mean } \pm \\
\text { SD) }\end{array}$ & \multicolumn{1}{|c|}{$\begin{array}{c}\text { Smoking } \\
\text { history }\end{array}$} & \multicolumn{1}{|c|}{$\begin{array}{c}\text { Increased Intraocular } \\
\text { Pressure }\end{array}$} \\
\hline Male $(n=21)$ & $44.3 \pm 12.6$ & 11 & $13(61.9 \%)$ \\
\hline $\begin{array}{l}\text { Female } \\
(n=39)\end{array}$ & $47.1 \pm 13.3$ & 2 & $5(12.8 \%)$ \\
\hline -value & $0.04 *$ & 0.201 & $0.01 *$ \\
\hline
\end{tabular}

The mean age in males is $44.3 \pm 12.6$ years and in females is $47.1 \pm 13.3$ years which was found to be statistically significant $(p<0.05)$. Increased Intraocular pressure was seen in hyperthyroid patients and the association was found to be statistically significant in Table 3 .

Table-4: Laterality status of orbitopathy in Hyperthyroid Patients $(\mathrm{N}=60)$.

\begin{tabular}{|l|l|l|}
\hline \multicolumn{1}{|c|}{ Laterality } & \multicolumn{1}{c|}{ No. of patients } & \multicolumn{1}{c|}{ Percentage } \\
\hline Unilateral & 29 & 48.3 \\
\hline Right eye & 13 & 21.6 \\
\hline Left eye & 11 & 18.3 \\
\hline Bilateral & 14 & 23.3 \\
\hline
\end{tabular}

In table 4 , the Laterality status of orbitopathy was analyzed. The most common presentation was found to be unilateral.

Table-5: Muscle involvement in Hyperthyroid Patients $(\mathbf{N}=60)$.

\begin{tabular}{|l|l|l|}
\hline \multicolumn{1}{|c|}{ Muscle involved } & \multicolumn{1}{c|}{ No. of patients } & \multicolumn{1}{c|}{ Percentage } \\
\hline Inferior rectus & 29 & 48.3 \\
\hline Medial rectus & 23 & 38.3 \\
\hline Superior rectus & 14 & 23.3 \\
\hline Lateral rectus & 7 & 11.6 \\
\hline
\end{tabular}

Table-6: Ocular Signs in hyperthyroidism patient.

\begin{tabular}{|l|l|l|}
\hline \multicolumn{1}{|c|}{ Sign } & No. of patients & Percentage \\
\hline Lid edema (Enroth's sign) & 7 & 11.6 \\
\hline Lid retraction (Dalrymple sign) & 11 & 18.3 \\
\hline Lid lag (Graefe's sign) & 13 & 21.6 \\
\hline Conjunctival congestion & 12 & 20 \\
\hline Corneal ulcer & 2 & 3.3 \\
\hline Scleral show & 9 & 15 \\
\hline Increased palpebral aperture & 17 & 28.3 \\
\hline Restrictive myopathy & 2 & 3.3 \\
\hline Refractive error & 19 & 31.6 \\
\hline
\end{tabular}


\begin{tabular}{|l|l|l|}
\hline Increase IOP with optic disk and visual field change & 11 & 18.3 \\
\hline
\end{tabular}

As table 5 shows the Inferior rectus muscle was the commonest muscle involved with $48.3 \%$ followed by the Medial rectus muscle $38.3 \%$, Superior rectus muscle $23.3 \%$, and Lateral rectus muscle involved least with $11.6 \%$ in descending order.

None of the patients reported a loss of vision. The most common sign refractive error and the least one was restrictive myopathy in Table 6.

Table-7: Distribution of presenting ocular signs in Hyperthyroid Patients $(\mathbf{N}=70)$.

\begin{tabular}{|l|l|l|l|c|}
\hline \multicolumn{1}{|c|}{$\begin{array}{c}\text { Mode of } \\
\text { presentation }\end{array}$} & \multicolumn{1}{|c|}{$\begin{array}{c}\text { Male } \\
(\mathbf{n = 2 1 )}\end{array}$} & \multicolumn{1}{|c|}{$\begin{array}{c}\text { Female } \\
(\mathbf{n = 3 9 )}\end{array}$} & $\begin{array}{c}\text { Total } \\
(\mathbf{N}=60)\end{array}$ & $\begin{array}{c}\mathrm{p}- \\
\text { value }\end{array}$ \\
\hline Proptosis & 11 & 29 & 40 & $<0.001$ \\
\hline Dry eye & 3 & 12 & 15 & $<0.001$ \\
\hline Upper lid retraction & 9 & 18 & 27 & $<0.001$ \\
\hline Decreased vision & 17 & 26 & 43 & $<0.001$ \\
\hline
\end{tabular}

As per Table 7, the most common presenting eye sign was found to be decreased vision during the study period in patients of Hyperthyroidism which was found to be statistically significant. $(p<0.05)$.

Table-8: Prevalence of hyperthyroid eye signs according to different age groups.

\begin{tabular}{|l|l|l|l|l|l|}
\hline \multicolumn{1}{|c|}{$\begin{array}{c}\text { Mode of } \\
\text { presentation }\end{array}$} & \multicolumn{1}{|c|}{ years } & \multicolumn{1}{|c|}{$\begin{array}{c}\mathbf{2 1 - 4 0} \\
\text { years }\end{array}$} & $\begin{array}{c}\mathbf{4 1 - 6 0} \\
\text { years }\end{array}$ & $\begin{array}{c}>61 \\
\text { years }\end{array}$ & $\begin{array}{c}\mathbf{p}- \\
\text { value }\end{array}$ \\
\hline Proptosis & 5 & 9 & 12 & 14 & 0.32 \\
\hline Dry eye & 1 & 2 & 3 & 9 & 0.23 \\
\hline Upper lid retraction & 2 & 3 & 8 & 14 & 0.03 \\
\hline Decreased vision & 4 & 9 & 13 & 17 & 0.01 \\
\hline
\end{tabular}

It has been clear as the age progresses the signs tend to increase in hypothyroidism patients. the decreased vision was found to be the most common eye sign among all age groups which was statistically significant. $(p<0.05)$ followed by Upper lid retraction (Table 8 ).

\section{Discussion}

The involvement of the eyes in thyroid disease is a well-acknowledged entity. In the present study, our objective was to determine the association of hyperthyroidism with raised IOP and Dry eye in a patient population is based on different age groups and gender. Most studies around the world have shown a higher female to male ratio [13].

The present study had a female to male was 2.1:1. Besharati et al. also found a higher frequency in females but Kashkouli et al reported more prevalent thyroid eye disease in males [14].
More than $80 \%$ of our patients were under the age of 50. Etezad- Razavi reported a mean of 34.7 years for females and 44.7 years for males, which is slightly different from our mean of 33.0 and 38.1 years for females and males, respectively [15].

As per the present study raised Intraocular pressure and Dry eyes were seen in our female population, our results were clinically significant $(P<0.05)$ One notable finding in this study was the elevation of IOP.

The orbit is a bony structure and an increase in intra-orbital volume will cause both displacements of the globe anteriorly and increased intraocular pressure [16]. The association of Hyperthyroidism with increased IOP has been known for more than a century.

Increased IOP in up gaze is commonly seen in hyperthyroidism however it is not specific and can be seen in any infiltrative orbitopathy due to mechanical compression of the globe. Besides, it has been proposed that thyroid-related ocular hypertension may be caused by increased episcleral venous pressure or glycosaminoglycan deposition in the trabecular meshwork [17].

In a study by Haefliger et al., performed on 500 patient charts, the prevalence of increased IOP was noted to be $24 \%$ [18]. In 2007, Behrouzi et al. reported a prevalence of $11 \%$, and He reported an incidence of $31.3 \%$ in Chinese patients [18]. With the persistence of exophthalmos, there was an increased chance of development and progression of glaucoma signs such as cupping of the disc and visual field defects. The present study had (36.6\%) cases of increased IOP in the primary position.

An increase in IOP can be explained by increased pressure on the globe by enlarging muscle masses and by the impediment of episcleral outflow. Increased IOP was seen more in men (36.6\%) than women $(10 \%), P=0.01$.

Persistence of hyperthyroidism may lead to a progressive increase of IOP, leading to overt manifestations of glaucoma such as cupping of the disc and visual field loss, therefore, follow-up of patients in this regard is warranted.

The studies by Besharati, Perros, and Lee also demonstrated the same trend $[19,20,21]$. It appears that even though dry eyes and raised intraocular pressure was more frequently seen in females, a more aggressive form is seen with increasing age and the male gender. 
The ocular complaint was observed in $44.27 \%$ of patients; foreign body sensation being the most common presenting symptoms in $61.79 \%$. In a study done by Kashkouli et al., bilateral proptosis $(9.9 \%)$, burning sensation $(5.4 \%)$, pain behind the eye $(5.3 \%)$, and puffiness $(4.7 \%)$ were the most common signs and symptoms [22]. According to Carlson SE, the frequency of decreased vision is $67 \%$ of having common symptoms [23].

Dry eye has historically been explained by increased tear evaporation from proptotic eyes $[24,25]$. Nonetheless recently it has been shown that the lacrimal gland may also be a target of TSH antibodies [26]. Clinical evidence of dry eye was noted in $12(17 \%)$ of our patients significant in women when compared to males.

When the dry eye was cross-referenced with the presence of proptosis, it was not found to be significant, indicating that lacrimal gland dysfunction should be considered as an entity by itself and not merely a consequence of proptosis. Interestingly, it has been shown by Gupta et al. that in patients presenting with dry eyes, previously undiagnosed thyroid dysfunction may be the underlying cause [27].

\section{Limitations}

- Since our sample size was small due to the lesser number of patients attending the outpatient department, this was insufficient to estimate the exact prevalence of ocular manifestations of thyroid disease

- Smoking has been shown to correlate with the severity of hyperthyroidism but in the present study there was only 13 smoker who had hyperthyroidism, yet there was not enough data to make a statistical statement.

- Some patients with TD were taking systemic steroid and other immunosuppressive drugs due to some other systemic disease, these drugs are known to be having anti-inflammatory effects, and this can be a confounding factor in the present study

- The presence of a severe degree of eye involvement in our set up may be due to late presentation and due to unawareness of their disease process at presentation. It may be due to our center being a tertiary eye center, and since the majority of complicated and referred cases are reported.

\section{Conclusions}

The prevalence of dry eye and raised Intraocular pressure in patients of hyperthyroidism was high and was more common in males. Dry eye and increased IOP have commonly seen outcomes that should be managed diligently.

\section{What does the study add to the existing knowledge}

This potential sight-threatening condition is seen worldwide and has many functional and cosmetic consequences that need to be recognized. Hyperthyroidism was significantly associated with the severity.

\section{Author's contribution}

\section{Dr. Madhuri Patil: Concept, study design}

Dr. M Gitanjali: Manuscript preparation

\section{Reference}

01. Lee HB, Rodgers IR, Woog JJ. Evaluation and management of graves' orbitopathy. Otolaryngol Clin North Am. 2006;39(5)923-942. doi: 10.1016/j.otc.2006.07.008 [Crossref]

02. Zhang J, Lazar MA. The mechanism of action of thyroid hormones. Annu Rev Physiol. 2000;62;439-66.

doi: 10.1146/annurev.physiol.62.1.439 [Crossref]

03. Metcalfe RA, Weetman AP. Stimulation of extraocular muscle fibroblasts by cytokines and hypoxia- Possible role in thyroid-associated ophthalmopathy. Clin Endocrinol (Oxf). 1994;40(1)67-72.

doi: $10.1111 / j .1365-2265.1994 . t b 02445 . x$ [Crossref]

04. Feely J, Isles TE. Screening for thyroid dysfunction in diabetics. $\mathrm{Br}$ Med $\mathrm{J}$. 1979;1(6179)1678.

doi: $10.1136 / \mathrm{bmj} .1 .6179 .1678$ [Crossref]

05. Bartley GB, Fatourechi V, Kadrmas EF, Jacobsen SJ, Ilstrup DM, Garrity JA, et al. Chronology of graves' ophthalmopathy in an incidence cohort. Am J Ophthalmol. 1996;121(4)426-434.

doi: $10.1016 / \mathrm{s} 0002-9394(14) 70439-8 \quad$ [Crossref] 
06. Palikhe S, Thakur A, Narayan SD, Sharma AK, Acharya N. Ocular manifestations in thyroid eye disorder- A cross-sectional study from Nepal. Int J Clin Med. 2016;7(12)814-823.

doi: $10.4236 / \mathrm{ijcm} .2016 .712088$ [Crossref]

07. Woo KI, Kim YD, Lee SY. Prevalence and risk factors for thyroid eye disease among Korean dysthyroid patients. Korean J Ophthalmol. 2013;27(6)397-404.

doi: $10.3341 / \mathrm{kjo} .2013 .27 .6 .397$ [Crossref]

08. Manji N, Carr-Smith JD, Boelaert K, Allahabadia A, Armitage M, Chatterjee VK, et al. Influences of age, gender, smoking, and family history on autoimmune thyroid disease phenotype. J Clin Endocrinol Metab. 2006;91(12)4873-4880.

doi: 10.1210/jc.2006-1402 [Crossref]

09. Kashkouli MB, Pakdel F, Kiavash V, Heidari I, Heirati A, Jam $S$, et al. Hyperthyroid vs hypothyroid eye disease- The same severity and activity. Eye (Lond). 2011;25(11)1442-1446.

doi: 10.1038/eye.2011.186 [Crossref]

10. Saks ND, Burnstine MA, Putterman AM. Glabellar rhytids in thyroid associated orbitopathy. Ophthalmic Plast Reconstr Surg. 2001;17(2)91-95.

doi: 10.1097/00002341-200103000-00003 [Crossref]

11. Jarusaitiene D, Verkauzskiene R, Jasinskas V, Jankauskiene VJ. Predictive factors of development of graves' ophthalmopathy for patients with juvenile graves disease. Int J Endocrinol. 2016;2016;9.

doi: $10.1155 / 2016 / 8129497$ [Crossref]

12. Cross JM, Girkin CA, Owsley C, McGwin G Jr. The association between thyroid problems and glaucoma. Br J Ophthalmol. 2008;92(11)15031505.

doi: $10.1136 /$ bjo.2008.147165 [Crossref]

13. Sultana S, Wadud SA, Huda S, Ahmed S. Open angle glaucoma and glaucoma suspect and ocular hypertension in thyroid related immune orbitopathy and thyroid disease. Bangabandhu Sheikh Mujib Med Univ J. 2015;8(1)50-55.

doi: 10.3329/bsmmuj.v8i1.28921 [Crossref]
14. Bartalena L, Tanda ML. Graves' ophthalmopathy. New Eng J Med. 2009;360(10)994-1001. doi: $10.1056 /$ NEJMcp0806317 [Crossref]

15. Etezad-Razavi M, Aboutorabi RB, ZareiGhanavati S, Daneshvar R. Prevalence and severity of ophthalmic manifestations of Graves' disease in Mashhad university endocrine clinics. Iran J Ophthalmol. 2006;19(3)14-21.

[Crossref]

16. Cockerham KP, Pal C, Jani B, Wolter A, Kennerdell JS. The prevalence and implications of ocular hypertension and glaucoma in thyroidassociated orbitopathy. Ophthalmol. 1997;104(6)914-917.

doi: $10.1016 / s 0161-6420(97) 30207-3$ [Crossref]

17. Jankauskiene J, Jakstaite V, Smalinskas V. Changes of vision and refraction in patients with thyroid pathology. Medicina (Kaunas). 2009;45(5)378-81.

[Crossref]

18. Haefliger I, von Arx G, Pimentel AR. Pathophysiology of intraocular pressure increase and glaucoma prevalence in thyroid eye disease- a mini-review. Klin Monatsbl Augenheilkund. 2010;227(4)292-293.

doi: $10.1055 / \mathrm{s}-0029-1245199$ [Crossref]

19. Besharati M, Rastegar A. Clinical study of ophthalmopathy in patients with Graves' disease. Asian J Ophthalmol. 2005;7(3)108112.

[Crossref]

20. Perros P, Neoh C, Dickinson J. Thyroid eye disease. BMJ. 2009;338;b560.

doi: $10.1136 /$ bmj.b560 [Crossref]

21. Lee A, Rochtchina E, Wang J, Healey PR, Mitchell P. Open-angle glaucoma and systemic thyroid disease in an older population. The Blue Mountains Eye Study, Eye Lond. 2004;18(6)600-608.

doi: 10.1038/sj.eye.6700731 [Crossref]

22. Kashkouli MB, Jam S, Sabzvari D, Ketabi N, Azarinia S, Seyed Alinaghi S, et al. Thyroidassociated ophthalmopathy in Iranian patients. Acta Medica Iranica. 2011;49(9)612-618.

[Crossref] 
23. Carlson SE, Werkman S, Rhodes P, Tolley E. Visual-Acuity Development in Healthy Preterm Infants- Effect of Marine-Oil Supplementation. Am J Clin Nutr. 1993;58(1)35-42.

doi: $10.1093 / a j c n / 58.1 .35$ [Crossref]

24. Chandrasekaran S, Petsoglou C, Billson FA, Selva D, Ghabrial R. Refractive change in thyroid eye disease (a neglected clinical sign). Br J Ophthalmol. 2006;90(3)307-309.

doi: $10.1136 /$ bjo.2005.078295 [Crossref]

25. Gürdal C, Saraç O, Genç I, Kırımlıoğlu H, Takmaz T, Can I, et al. Ocular surface and dry eye in graves' disease. Curr Eye Res. 2011;36(1)8-13.

doi: $10.3109 / 02713683.2010 .526285$ [Crossref]
26. Eckstein AK, Finkenrath A, Heiligenhaus A, Renzing-Köhler K, Esser J, Krüger $C$, et al. Dry eye syndrome in thyroid-associated ophthalmopathy- Lacrimal expression of TSH receptor suggests involvement of TSHRspecific autoantibodies. Acta Ophthalmol Scand. 2004;82(3 pt 1)291-297. doi: $10.1111 /$ j.1395-3907.2004.00268.x [Crossref]

27. Behrouzi Z, Rabei HM, Azizi F, Daftarian N, Mehrabi $Y$, Ardeshiri $M$, et al. Prevalence of open-angle glaucoma, glaucoma suspect, and ocular hypertension in thyroid-related immune orbitopathy. J Glaucoma. 2007;16(4)358-362.

doi: $10.1097 /$ IJG.0b013e31802e644b [Crossref] 